\title{
The influence of external mechanical impact on the dynamics of an electromagnetic actuator
}

\author{
Irina Bolshenko ${ }^{1}$, Denis Batishchev ${ }^{1, *}$, and Yuri Klimenko ${ }^{1}$ \\ ${ }^{1}$ Platov South-Russian State Polytechnic University (NPI), Research Institute of Electromechanics, 346428 Novocherkassk \\ Prosveshcheniya St. 132, Russian Federation
}

\begin{abstract}
A special case of studying the external mechanical acting factors - impact - influence on the electromagnet actuator dynamic characteristics is considered. An algorithm is proposed and software tools for its implementation are determined. The results of mathematical simulation are obtained, and their analysis is performed.
\end{abstract}

\section{Introduction}

The problems of construction of driving electromagnetic mechanisms with the specified noise and vibration levels occurred rather long ago [1]. They are especially acute in the automobile and shipbuilding industries, in the design of power plants mechatronic modules of autonomous transport systems including submarine and super marine vehicles. Initially their solution was reduced to the study and development of different methods for electromechanical transducers vibration and noise reducing. With the requirements strengthening in general and with the special low-noise and low-vibration electromechanical converters emergence occurrence, it became evident that in many cases the issues of providing requirements in terms of vibration and noise characteristics (VNC) must be solved at the devices design stage. The results of the research and ways to ensure the VNC were summarized in VNIIEM at the development of a low noise electrical machine design system [1]. However, despite existing progress in the field of vibration and noise research, for the driving electromagnetic mechanisms there is no possibility to predict their levels with the acceptable accuracy at the design stage. To the new autonomous transport systems being created, the high requirements not only on the level of comfort, but also on the possibility of detection due to the increased level of noise are applied. The devices' noise and vibration form the underwater noise of Navy ships and submarines worsening their furtively. The most "noisy" are the electromagnet actuators (EMA) used as valve actuators in control circuits, hydraulic and pneumatic control systems switchgears, fuel supply and air-and-gas exchange devices of internal combustion engines.

The previously conducted researches [2-5] aimed at studying the possibilities to create EMA resistant to mechanical impact factors (IMF) have shown that in order to obtain the specified dynamic properties that ensure the stable operation of the electromagnetic mechanism under vibration conditions, it is reasonable to use the integrated approach based on the definition and implementation of the required control law taking into account the configuration, geometric relationships and features of the electromagnet design.

In the works presented before the main emphasis was made on the research of external vibration loads effect on the EMA dynamic characteristics. In the present work the emphasis is made on the research of the various impact mechanical action parameters influence on the electromagnetic drive response dynamics at the design work stage. Among the external factors affecting the EMA it is necessary to note the mechanical effects, impact being the most dangerous of which. The most possible reasons of impacts actions on the products may be collisions, explosions, supersonic pressure, accidental falls, etc. The named effects can occur during the EMA exploitations at airplanes, ships, rockets, vehicles, as well as during their transportation.

\section{Research method}

To conduct the research, the approach that has proved itself to be successful in performing studies about the vibration effect on the electromagnetic drive characteristics was used [2]. At the development of the model the FEMM 4.2 software package [6] in conjunction with the LTspice $I V$ package [7] was used. The choice of this approach is due to the possibility of free distribution and usage of the named software for commercial purposes. For example, to conduct such a research with the widely used ANSYS software it is necessary to use the ANSYS Maxwell $(\$ 39,664.22)$ and ANSYS Simplorer Advanced (\$ 31,133.49) [8] which is not reasonable within the framework of the research performed.

As an object of research the device for the back-run choice line electrical interlocking being developed for

\footnotetext{
* Corresponding author: batishchevd@gmail.com
} 
the concept cars of the VAZ-2116, 2117 and 2118 type platforms was adopted (Figure 1) [9, 10].
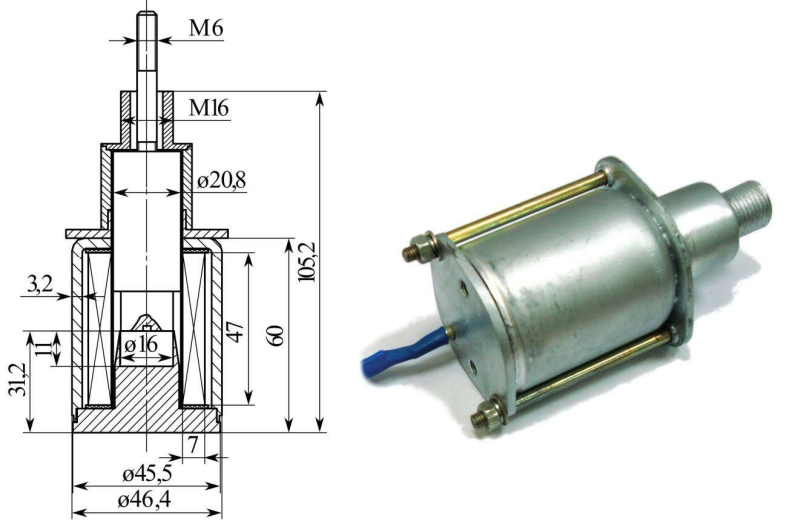

Fig. 1. Gear Shift Lock Solenoid.
Based on the solution of the field problem (Figure 2) families of characteristics $\Psi=f(i, x)$ and $P_{\mathrm{em}}=f(i, x)$ were formed for further use in the LTspice program (Figure 2). The families of characteristics were calculated in the automatic mode using scripts written in the Lua programming language.

In the case of impact load simulation, the model of the impact load source was represented as a functional voltage source Bimp (Figure 3d). At this the main parameters of the impact pulse (Figure 3a-c) - the shock acceleration peak value (A), the impact pulse duration (D) and the impact pulse form - the law of the acceleration variation over time were specified in accordance with GOST 28213-89 [11], supposing that the result of the impact loads effect on the product is determined by its dynamic behavior that are characterized by its mass, toughness and natural oscillations frequency.
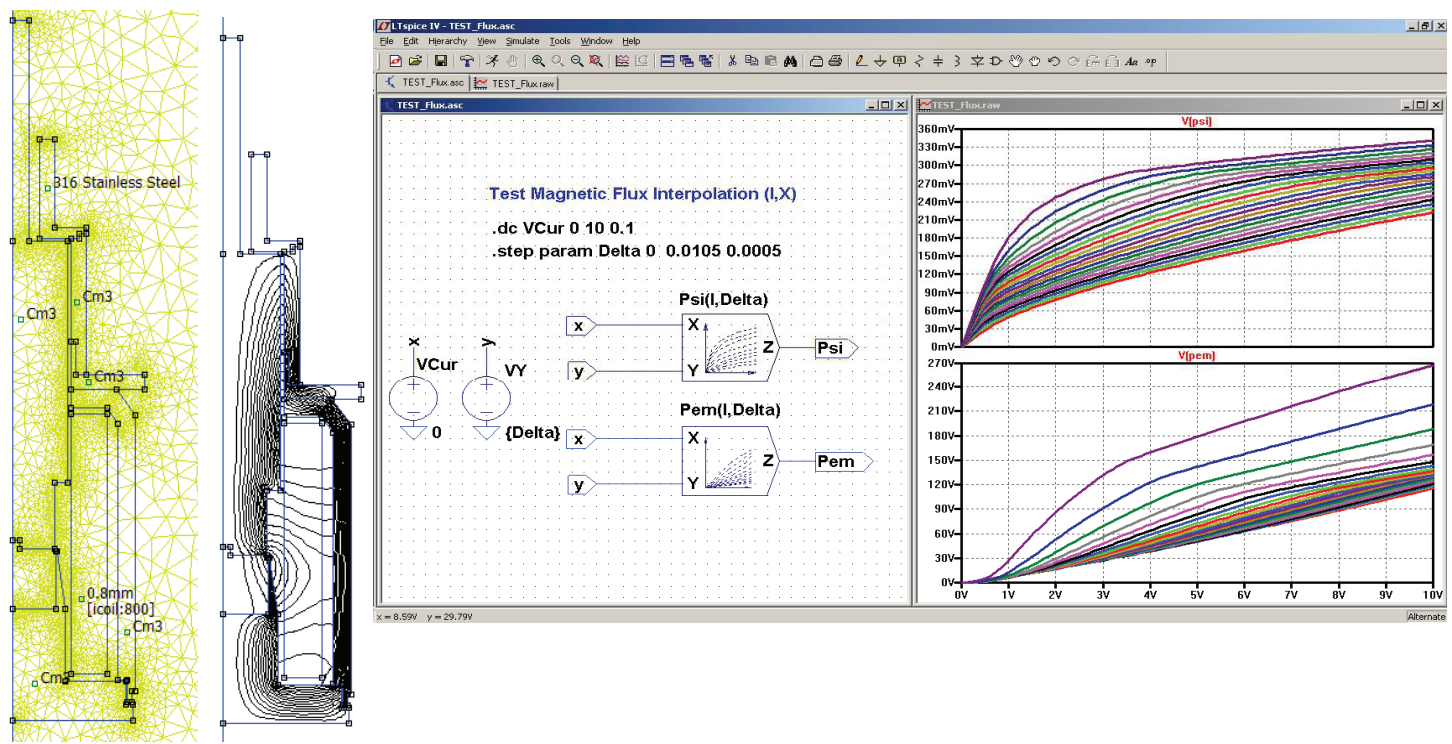

Fig. 2. The results of the field calculation for the EMA and the family of the drive characteristics $\Psi=f(i, \delta)$ and $P_{\mathrm{em}}=f(i, \delta)$.

The impact pulse of the half-sine shape is used the most often in the tests (Figure 3a).

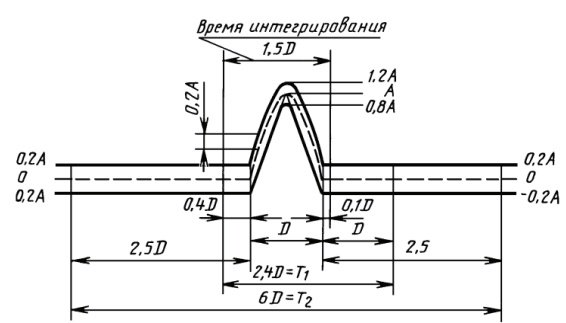

a)

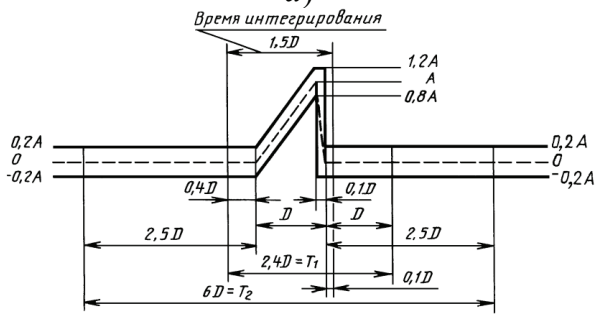

b)

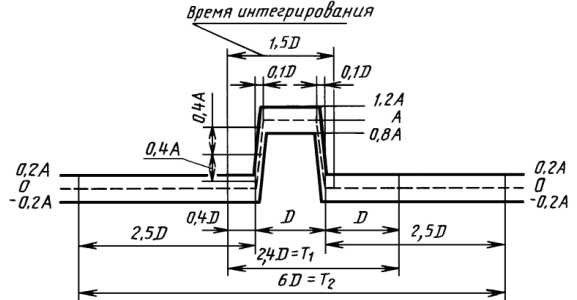

c)

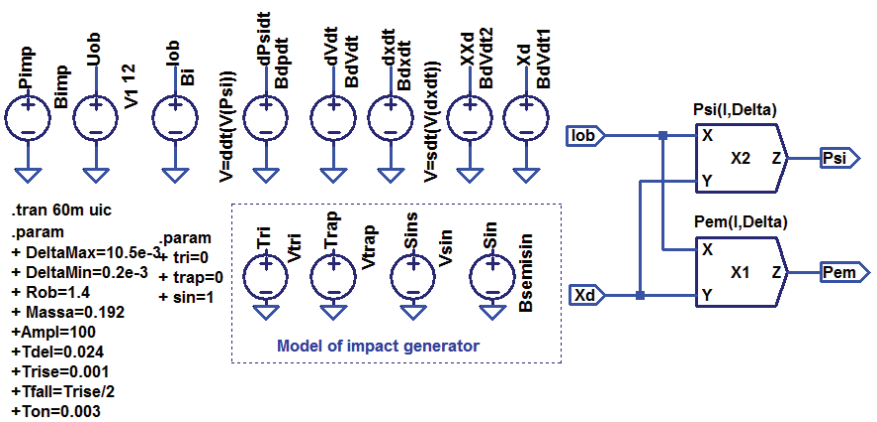

d) 


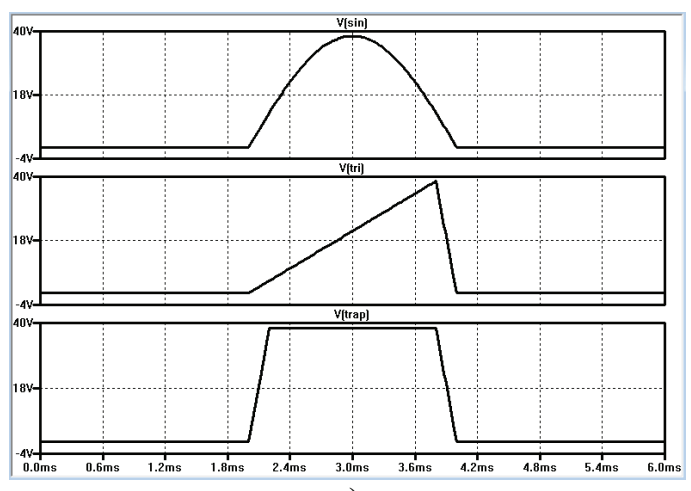

e)

Fig. 3. The forms of the impact pulses $(a-c)$ and their representation in the LTspice program $(d, e)$ : a) the half-sine pulse; b) the saw tooth pulse with the peak at the end; c) trapezoidal impulse.
According to GOST 17516.1-90 [12] the articles installed in mobile railless complete products belong to the mechanical design group M30. This imposes the following requirements in terms of resistance to the IMF and in particular to impacts: the shock acceleration peak value of single shot impacts is $200 \mathrm{~m} \mathrm{~s}^{-2}(20 \mathrm{~g})$, the duration of shock acceleration peak value of single-shot impacts is $2 \mathrm{~ms}-15 \mathrm{~ms}$. Such impact level is high $[12,13]$.

\section{Results and discussion}

The results of the single shock impact on the dynamic performance simulation (speed $V(d x d t)$, motion $V(x d)$ and winding current $V(i o b))$ in the direction of external actions coinciding with the direction of armature movement and directed in the opposite direction are shown in graphs (Figure 4, Figure 5) .
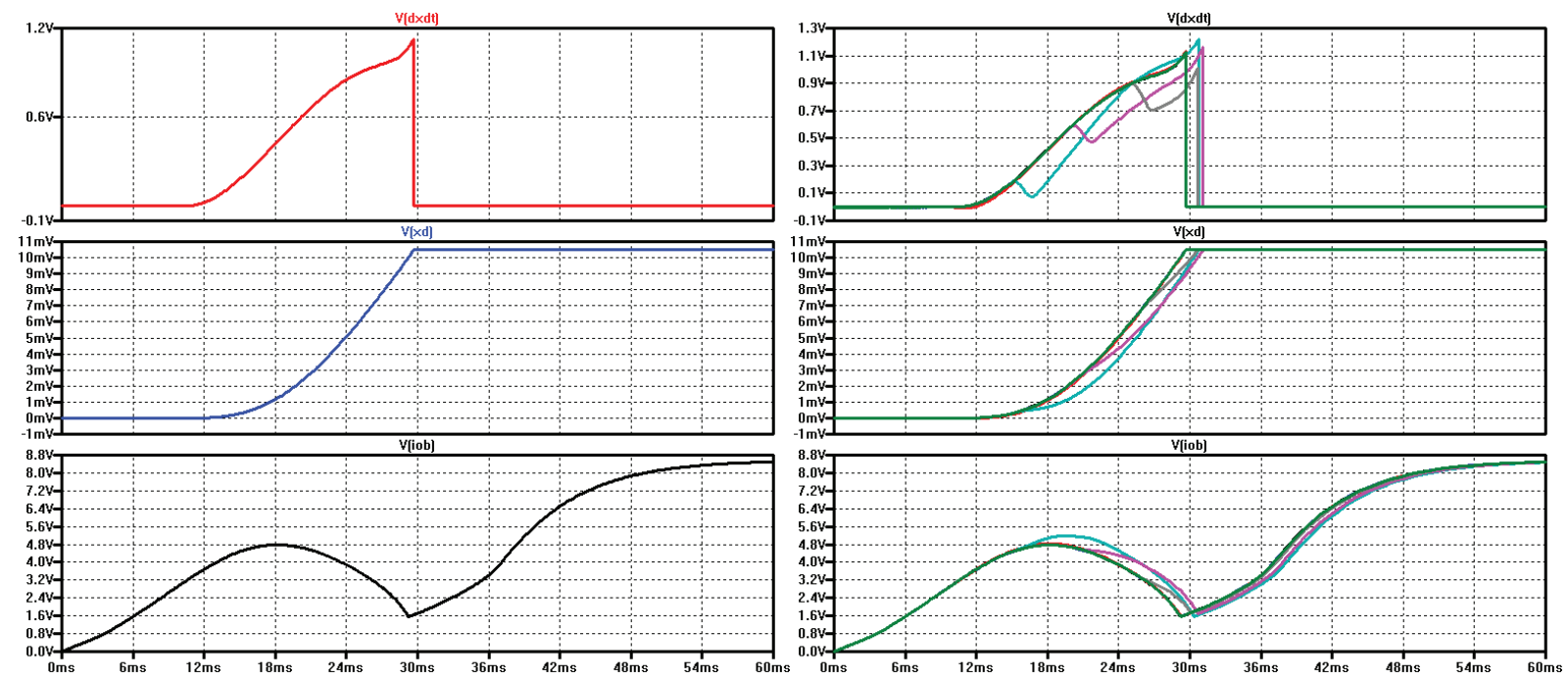

Fig. 4. The results of the single shock impact, the half-sine pulse with the duration of $2 \mathrm{~ms}$ at the variation of the shock impact action from 0 to $30 \mathrm{~ms}$ (the characteristics without the EMA are represented in the left side).

The results of the single stroke impact simulation, the half-sine pulse with the duration from 2 to $14 \mathrm{~ms}$ are shown in Figure 5, the moment of the impulse generation

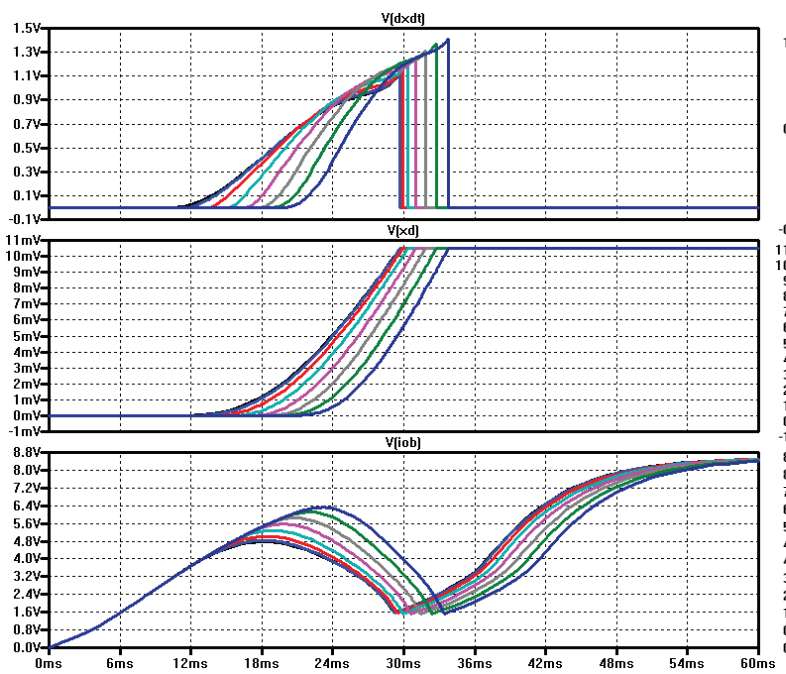

at the beginning of the electromagnet armature moving, $11 \mathrm{~ms}$ (left graph) and at the moment corresponding to half of the armature movement path, $24 \mathrm{~ms}$ (right graph).

Fig. 5. The results of the single stroke impact simulation of the half-sine shape at the pulse duration variation. 


\section{Conclusion}

Basing on the results of the presented studies it can be seen that the impact load influence significantly affects both the EMA response time and the terminal speed, i.e. on the drive VNC. It is possible to ensure the stability and required parameters of the VNC EMA either due to the rational shape of the working gaps bearing surfaces and the controlled conductivity of the workless gaps [14, 15] or due to the external influence on the control signal -the coils voltage supply forcing or applying special circuits for controlling their power [16-20].

Within the framework of the present article a small part of the research associated with the consideration of the impact load influence on the EMA dynamic characteristics is presented. More complete information will be provided in subsequent articles and in generalized STS.

The research was performed funded with the Russian Science Foundation grant (project № 17-79-10055).

\section{References}

1. V.A. Voronkin, V.Ya Gecha, E.A. Gorodetsky, V.V. Evlanov, A.B. Zakharenko, B.I. Zubenkov, A.I. Kaplin, V.I. Ledovskoi, I.V. Sklyarova, L.P. Smirnova, M.H. Shapiro, The electromechanics issues. Works of VNIIEM, 103 (2006)

2. D.V. Batishchev, Methods and algorithms for electromagnetic drives designing with account of the external vibration effects (dissertation in support of candidature for the technical degree, Novocherkassk, 2011)

3. Y.I. Klimenko, D.V. Batishchev, A.V. Pavlenko, V.P. Grinchenkov, Russ. Electr. Eng. 10, 588-593 (2015)

4. A.V. Pavlenko, D.V. Batishchev, A.A. Gummel, I.A. Bolshenko, Russian Electromechanics, 3, 17-27 (2017)

5. I.A. Bolshenko, The electromagnetic drive of the gas-distributing mechanism valve of the internal combustion engine (dissertation in support of candidature for the technical degree, Novocherkassk, 2015)

6. D.C. Meeker, Finite Element Method Magnetics, Version 4.2, available at: http://www.femm.info/ (free)

7. LTspice Simulation system description, available at: http://LTspice.linear-tech.com/software/scad3.pdf (free)

8. General Services Administration (GSA), Price List Current Through Modification \#PS-0081, (2017)

9. D.V. Batishchev, V.V. Medvedev, University News. North-Cauc. Region. Techn. Scien., Spec.Iss., 54-56 (2005)
10. The power interlocking of the back-run choice line. Technical requirements for the cobbled unit (Scientific and Technical Center of JSC AVTOVAZ, 2002)

11. GOST 28213-89 The basic methods of testing for external factors influence. Part 2. Trials. The Ea test and the Manual: Single Stroke (1989)

12. GOST 17516.1-90 The electrotechnical products. General requirements regarding the mechanical external factors resistance (1990)

13. GOST 30631-99 General requirements for Machines, instruments and other industrial products in terms of resistance to mechanical external influencing factors during operation (1999)

14. A.V. Pavlenko, D.V. Batishchev, University News. North-Cauc. Region. Techn. Scien., Spec.Iss., 24 (2003)

15. D.V. Batishchev, University News. North-Cauc. Region. Techn. Scien., Spec.Iss., 11-13 (2009)

16. A.G. Butkovsky, Yu.A. Cherkashin, The optimal control of the electromechanical DC devices (1972)

17. Yu.A. Cherkashin, The optimal control of the electromechanical devices (1969)

18. A.V. Pavlenko, V.P. Grinchenkov, D.V. Batishchev, A.A. Gummel, I.A. Pavlenko, E. Kallenbach, The electromagnet drives for the mechatronic devices and vehicle systems. Design and optimization (Mechatronics, automation, management, Taganrog, 2007)

19. A.V. Pavlenko, A.A. Gummel, I.A. Bolshenko, Proc. Eng., 129, 571-577 (2015)

20. A.V. Pavlenko, A.A. Gummel', D.V. Batishchev, E. Baumbach, Russ. Electr. Eng. 4, 189-193 (2016) 